\title{
Reseña de Vega, Lope de Arte nuevo de hacer comedias: Edición crítica. Fuentes y ecos latinos, edición crítica y anotada de Felipe B. Pedraza Jiménez, Fuentes y ecos latinos: Pedro Conde Parrado, Cuenca, Ediciones de la Universidad de Castilla-La Mancha, 2016, 978 pp. ISBN: 978-84-9044-222-7
}

\section{Guillermo Gómez Sánchez-Ferrer}

Universidad de Valladolid

ESPAÑA

guillermo.gomez.sanchez-ferrer@uva.es

[Hipogrifo, (issn: 2328-1308), 6.2, 2018, pp. 825-831]

Recibido: 06-08-2018 / Aceptado: 17-09-2018

DOI: http://dx.doi.org/10.13035/H.2018.06.02.57

Aunque el Arte nuevo de hacer comedias de Lope de Vega ha conocido numerosas ediciones, tanto en publicaciones dirigidas a lectores no especializados como en otras pensadas para los estudiosos del Siglo de Oro, probablemente ninguna alcance el rigor y la profundidad del monumental asalto a la preceptiva del Fénix que han llevado a cabo Felipe B. Pedraza y Pedro Conde. Esta nueva edición ha visto la luz en un volumen de casi mil páginas, en la colección que la Universidad de Castilla-La Mancha reserva para las ediciones críticas. En ese espacio se encuentra, por tanto, precedida por otras publicaciones relacionadas con los proyectos de investigación del Instituto Almagro de Teatro Clásico, entre las que destacan los varios volúmenes de Comedias de Francisco de Rojas Zorilla, las Academias morales de las musas de Antonio Enríquez Gómez o La vega del Parnaso de Lope de Vega.

Dado ese inmejorable pórtico de entrada, el lector ya podrá suponer que la reciente publicación incluye una cuidada edición crítica de la obrita del Fénix, pero decir simplemente eso sería no hacer justicia a lo que Pedraza y Conde nos ofrecen en su libro. El Arte nuevo viene acompañado en esta ocasión de muchos otros materiales de indudable valor para los investigadores interesados en la literatura del siglo XVII; tantos que hacen que casi pase inadvertida la labor ecdótica entre los 
extensísimos comentarios y notas que envuelven a la obrita propiamente dicha. El libro se nos presenta desde el título como la reunión de dos trabajos distintos: una rigurosa edición de la preceptiva lopesca y una nueva versión castellana de otros textos fundamentales para su comprensión, presentados bajo el epígrafe «Fuentes y ecos latinos». Con todo, basta con repasar el índice para percatarse enseguida de que esas dos partes se multiplican considerablemente hasta llegar a componer casi una enciclopedia del teatro del Siglo de Oro y de sus preceptivas. La primera parte, a cargo de Felipe B. Pedraza, se compone de tres secciones: un estudio introductorio al Arte nuevo, la edición crítica propiamente dicha del texto y un amplísimo apartado (el más largo del libro) en que se recoge una serie de sustanciosas «Notas y escolios» al tratadito lopiano.

En el «Estudio» se esmera Pedraza por ofrecer un resumen de los temas fundamentales para acercarse al Arte nuevo. Haciendo siempre gala de la visión de conjunto que le confieren sus muchos años de estudio sobre Lope de Vega y su obra, el investigador establece un nutrido diálogo con buena parte de la crítica -las más de setenta páginas de la bibliografía final reflejan bien hasta qué punto se tiene en cuenta lo que otros han dicho- para pasar revista a sus aspectos más relevantes. Se detiene, en primer lugar, en las cuestiones estrictamente textuales: fecha de composición, género, fuentes y estructura. En esa parte ya queda claro que Pedraza no se limita a dar los datos básicos sobre el Arte nuevo. Desde las primeras páginas se puede observar el esfuerzo que hace por repensar las conclusiones alcanzadas en trabajos previos. Así, por ejemplo, se expone la difundida división de la pieza lopesca propuesta por Rozas (que entiende la obra del Fénix como un discurso académico compuesto por una parte prologal, una parte doctrinal, subdividida en compositio, elocutio, inventio y actio, y una parte epilogal) para revisar, a continuación, la división que el mismo Pedraza propusiera en su edición de las Rimas (1993-1994, [Cuenca], Universidad de Castilla-La Mancha) (25-28). En este sentido, sostiene que la piececilla lopesca, como «parodia sonriente del academicismo» (26) que es, puede dividirse en un exordio, un status quaestionis dedicado a la comedia antigua, una sección de enlace (en la que aparece citado Robortello), un largo apartado de exposición de la tesis en que se dan los elementos propios de la fórmula de la comedia nueva y un epílogo, que incluye una definición en latín de la comedia y una coda al lector (26-27). De esta manera, se ofrece una división del texto capaz de trascender los acercamientos estrictamente temáticos que, además, actualiza las propuestas previas de Rozas y del propio Pedraza.

Los siguientes apartados (31-52) abundan en el contexto en que surgió el Arte nuevo y en su posterior fama y fortuna. Allí se vuelven los ojos al impacto del texto en su momento para reivindicar que, «contra lo que acostumbra a decirse y a creerse, la intelectualidad española contemporánea (también gran parte de la europea) estuvo decididamente a favor del nuevo teatro, y de acuerdo con los aforismos condensados en el Arte nuevo» (35). El tema ha sido también ampliamente tratado en los dos volúmenes de los Cuadernos de Teatro Clásico coordinados precisamente por Pedraza y Rodríguez Cáceres (El teatro según Lope de Vega, de 2009, y El Siglo de Oro habla de Lope, de 2011) y de ellos se extractan aquí los testimonios más interesantes (31-37). Carlos Boyl, Miguel de Cervantes, Agustín de Rojas Vi- 
Ilandrando, Ricardo de Turia, Diego de Colmenares, Tirso de Molina, Alfonso Sánchez, Francisco Cascales o Francisco Pérez de Amaya, entre otros, vienen a demostrar la difusión del Arte nuevo y, sobre todo, de la manera de hacer comedias que allí se detalla.

Con igual acierto recupera Pedraza las noticias que surgieron sobre el tratadito tras la muerte del poeta. Inicia así un recorrido que va de Pérez de Montalbán o Antonio de León a Martínez de la Rosa; de Georges de Scudéry a Andrea Perrucci, pasando por Juan Caramuel o Nicolás Antonio. En esta sección se van desgranando las opiniones más relevantes para entender no solo el texto sino los contextos en los que ha suscitado interés, por una u otra razón. De este modo, se presta especial atención a las lecturas que en cada momento se privilegiaron a la hora de acercarse al texto, ya se entendiese como palinodia exculpatoria o ya como discurso irónico. Tampoco se olvidan en estas páginas iniciales las ausencias más notables: como bien señala Pedraza, ciertamente llama la atención que la pieza del Fénix no se encuentre ni siquiera aludida en los estudios sobre Lope de Schlegel o de Sismondi.

Así, en un flujo de ideas capaz de sintetizar la adversa y próspera fortuna del Arte nuevo, se enlaza, desde el parecer de los preceptistas ilustrados y románticos, con la crítica decimonónica de lord Holland, Böhl de Faber, el conde de Schack o Menéndez Pelayo; aspecto que sirve de pórtico, a su vez, para la última parte de la introducción (52-65). En ella se enfatizan las nuevas lecturas que se le han dado al poema desde mediados del siglo XIX hasta llegar a los congresos y las ediciones que, ya en pleno siglo XXI, quisieron conmemorar su cuarto centenario. Se cierra esa parte del «Estudio» poniendo de manifiesto, además, la actualidad de la poética lopesca de una manera muy singular: se alude a los «Hijos peregrinos del Arte nuevo», hombres y mujeres de teatro como Laila Ripoll y Álvaro Tato que, de un modo u otro, han sido capaces de integrar las enseñanzas del «monstruo de naturaleza» en su actividad sobre las tablas.

Las últimas páginas de la sección introductoria repasan la «singular fortuna editorial y crítica» (66) del Arte nuevo para detenerse, a continuación, en los «Criterios de edición», en los que insiste Pedraza en que, «si "desde el trabajo de Juana de José Prades, todos venimos prefiriendo el texto de 1613 [...], no es porque sea una edición más limpia o menos errada que el resto, sino porque no hay duda de que un corrector que conocía bien el texto del Arte nuevo subsanó algunos errores" graves y que no era fácil enmendar sin un íntimo conocimiento del escrito (...). De la misma forma, podemos decir que seguimos el de 1613, restableciendo el adecuado uso del sangrado de los párrafos y sustituyendo las lecturas erróneas que lo afean, por las propias y genuinas que nos ofrecen otros testimonios» (78).

En toda esta primera parte queda clara la atención con la que se han leído los trabajos dedicados al Arte nuevo. Aunque no se citen todos con igual profundidad, no hay duda de que Pedraza bebe de ellos para argumentar siempre por favor de la lectura más razonable. Se esfuerza, asimismo, por enfatizar el «risueño juego, con frecuencia irónico y en no pocas ocasiones cínico» (55), que entiende que es el Arte nuevo y resalta a menudo como una de las principales claves de lectura «el derecho 
del espectador a ser complacido por el artista» (174). Así, sin evitar los posibles conflictos que suscita el tratadito, tanto en la presentación de la obra como en las notas logra ofrecer una síntesis de conjunto que, desde el respeto por el trabajo de los investigadores citados, es capaz de encontrar la mejor interpretación de cada pasaje. Su amplia perspectiva le permite atender a juicios tan dispares (cronológica e ideológicamente) como los de Morel-Fatio, Menéndez Pelayo, Vossler, Menéndez Pidal, Rozas, Orozco Díaz, José Prades, Froldi, Profeti, Vitse, Canavaggio o Spang, entre muchos otros. Todos ellos están presentes tanto en el prólogo como, sobre todo, en las detalladas «Notas y escolios al Arte nuevo de hacer comedias» (101-635). En esas páginas, Pedraza repasa la obra párrafo a párrafo y verso a verso para profundizar en las ideas expuestas en la primera parte, extenderse en cuestiones puramente textuales, contextualizar las referencias a otros tratados - españoles y europeos - de carácter similar y abordar desde el rigor filológico las lecturas propuestas por los estudiosos.

El resultado de esta amplia sección es una monumental obra de erudición que plantea un rico comentario a lo más interesante de la obra y la crítica lopesca, con las completas ediciones del Arte nuevo de José Prades, Rozas, Profeti y Rodríguez Cuadros a la cabeza. No en vano, el propio Pedraza considera ese último acercamiento al texto lopesco como «una ambiciosa monografía que aborda los capítulos que hay que atender para una cabal comprensión del tratadito (...) Un estudio imprescindible, y muy bien escrito, que citaré, seguiré y discutiré en las notas de esta edición» (65). Lo mismo podría haberse dicho también de los otros trabajos mencionados.

Incidiendo a menudo en las características discursivas de la pieza, se destacan en estos comentarios todos los aspectos fundamentales de la poética lopesca: desde la identificación y el sentido de las alusiones que aparecen en el texto hasta la presencia de las convenciones teatrales de la época como contrapunto para explicar las menciones más ambiguas, pasando por la ejemplificación con innumerables pasajes -lopescos o no- de contenido análogo y la importancia de los aspectos formales del verso en la fijación del texto. Toda esa información -que resulta muy difícil de resumir y sistematizar en tan poco espacio- permite al lector interesado salir con una idea más que cabal de lo que fue en su momento y lo que ha supuesto para los posteriores lectores el Arte nuevo. Sin embargo, de entre todos los aspectos dignos de elogio en relación con estas «Notas y escolios», quizá lo más enriquecedor sea la finura con que Pedraza lee y explica, frase a frase, la obra. En su exégesis prima el sentido común a la hora de dar una interpretación, por encima de cualquier tipo de rocambolesca explicación erudita; que no faltan entre los trabajos dedicados al tratadito lopesco, como las propias notas se encargan de exponer en los lugares oportunos.

Todo lo anterior está arropando, como no podía ser de otro modo, una edición crítica largamente meditada, en la que el texto se fija tras presentar numerosas consideraciones de especial relevancia, desde un punto de vista ecdótico. Quizá el caso más interesante, en este sentido, se encuentre en el v. 43. Sirva, pues, de ejemplo del cuidado con que se ha tratado todo el texto. A propósito de ese pasa- 
je, Pedraza plantea las distintas lecturas que se encuentran en la tradición para mantener la de la versión de 1613 - su texto base-, pero lo hace justificando por extenso su elección con motivos estilísticos, en los que el ritmo del endecasílabo juega un papel fundamental. Además, el editor deja constancia de la ponderada labor que se esconde detrás de cada decisión al plantear (con la ayuda de Conde Parrado) que: «Lope tuvo que escribir "por que nò me den vóces,/ que süéle" (...). Esta enmienda supone que los cajistas compusieron para en vez de por (con valor final). Una lectio facilior que intercambiaba dos sinónimos que desempeñan la misma función sintáctica, sin reparar en que computan de forma distinta a efectos métricos (...) pero el resultado rítmico es poco más feliz que el texto deturpado que nos han legado las primeras ediciones. Por eso no me he atrevido a incorporar la enmienda al texto principal» (167-168).

El ánimo conservador con que se enfrenta Pedraza al texto a la hora de introducir enmiendas como esta se compensa ampliamente, como se puede observar, con las prolijas explicaciones que le dedica a cualquier cuestión crítica, por nimia que pueda parecer. Esa es la razón que parece haberle animado a incluir en el aparato crítico no solo las variantes textuales sino también las cuestiones ortográficas y las erratas más notables. Esos casos, aunque quizá habría sido preferible reservarlos para un aparato independiente que acompañase la versión del texto que se incluye en las «Notas y escolios» (manteniendo, por tanto, en la edición solamente las variantes con claro valor textual), añaden una gran riqueza al estudio ecdótico del Arte nuevo. Basta con echar un vistazo a la importancia que tiene el uso de signos parentéticos en los primeros diez versos de la pieza, expuesto con detenimiento por Pedraza en sus comentarios, para darse cuenta de ello (119-120).

Asimismo, a todo lo expuesto hasta aquí hay que sumar el gran acierto de incluir en esta nueva edición del Arte nuevo los textos latinos en los que se basa su contenido. La segunda mitad del volumen, a cargo de Pedro Conde, presenta una nueva traducción y edición (acompañada de sus correspondientes introducciones y notas) de cuatro textos esenciales para contextualizar adecuadamente la poética lopesca. Se trata de las dos principales «fuentes» manejadas por Lope (el tratado Sobre la comedia de Evancio-Donato y la Explicación de todo lo que atañe al arte de la comedia de Robortello) y dos «ecos latinos» derivados del propio Arte nuevo (el apéndice de la Expostulatio Spongiae de Alfonso Sánchez, preparado para la ocasión en colaboración con Xavier Tubau, y la Epístola XXI del Primus calamus de Caramuel).

Las cuatro obras, reiteradamente citadas en relación con la preceptiva del Fénix, eran en algunos casos de muy difícil acceso para los estudiosos de la literatura española. Digno de agradecer es, por tanto, su inclusión en este volumen, sobre todo porque, cuando existían ediciones y traducciones precedentes, Conde las ha tenido muy en cuenta y no ha dudado en enmendarlas si considera justificadamente que es necesario. En este sentido, se nos ofrece «una traducción alternativa [de la Explicatio eorum omnium quae ad comoediae artificium pertinent de Robortello] a la correcta ofrecida por [María José] Vega y una edición del texto latino que creemos mejora bastante el que ella ofrece, único punto débil, a nuestro juicio, de su obra» (674). De manera similar, se ponen de manifiesto -tanto en la introducción como 
en la edición y en la traducción- los aspectos más relevantes para entender una obra tan críptica como la Expostulatio Spongiae de Alfonso Sánchez, incluyendo algunos de gran importancia que se omiten en la última edición del texto. Finalmente, se incluye también una nueva edición y traducción tanto del tratado Sobre la comedia de Evancio-Donato, preparadas a partir de las de Cupaiouolo y Wessner (642-643), como de la Epístola XXI de Caramuel, que se sirve de la versión comentada de Héctor Hernández Nieto (767). Desde luego, el mimo con que se tratan estos textos pone de manifiesto la labor de puesta al día que ha hecho Conde (en el caso de la Expostulatio Spongiae, junto a Tubau) para que esta segunda parte del libro sea lo más útil posible a todos los interesados por el teatro áureo. Gracias a su trabajo, disponemos ahora de una traducción en la que se pueden leer los tratados que dieron forma a las ideas del Arte nuevo en edición bilingüe, con los textos (en latín o griego y castellano) en páginas confrontadas, pertinentemente presentados y anotados.

Es indudable la riqueza que alcanza la propuesta dramática lopesca al verla a la luz de estos textos. Precisamente para facilitar esa labor a los lectores, Conde se toma la molestia de complementar el -ya de por sí extensísimo- comentario previo de la obra del Fénix indicando, en las notas a la versión en castellano o en apéndices sinópticos, «las partes citadas, resumidas o parafraseadas por Lope en el Arte nuevo» (643). Por si fuera poco con eso, al acudir a tales notas el lector interesado verá además constantes referencias a los pasajes que tratan de materia análoga en el resto de tratados latinos publicados y otros jugosos comentarios sobre las traducciones que se hicieron de ellos en el siglo XVII.

A todo lo anterior hay que añadir que el libro se cierra con un práctico índice de materias, obras y autores. Desde luego, no podemos más que insistir en que esta nueva edición del Arte nuevo ofrece mucho más de lo que promete en su título. No se trata tan solo de un acercamiento exegético a la pieza, sino de una obra de conjunto capaz de condensar la historia del texto y de sus lectores, desde 1609 hasta nuestros días. De hecho, aunque Pedraza se disculpa en la introducción por «añad[ir] un nuevo título, voluminoso, quizá prolijo, a la larga serie» de estudios que ya existen sobre el Arte nuevo (81), pocos podrían haber preparado una edición crítica y comentada con un detenimiento, una profundidad y un acierto como los que se aprecian aquí.

En definitiva, aunque en las «Palabras preliminares» se indica que esta edición «llega con unos años de retraso» (9), creemos que no ha hecho sino esperar al momento oportuno. Es cierto que no ha visto la luz aprovechando los fastos de la conmemoración que, en 2009, recorrió numerosas universidades con encuentros centrados de manera específica en el Arte nuevo. No obstante, es precisamente esa circunstancia la que les ha permitido a Felipe B. Pedraza y Pedro Conde tener una mejor perspectiva de lo que en su día fue una inundación de estudios. El paso del tiempo ha asentado las aportaciones más interesantes de entre las que surgieron con motivo del centenario, situación que les ha permitido a Pedraza y a Conde nutrirse de los trabajos más relevantes para abordar «esta nueva edición del Arte nuevo, con sus escolios, fuentes y ecos» (14). Ellos mismos dan cuenta de que «en 
estos años han ido surgiendo nuevos estudios sobre el discurso académico de Lope, se han publicado las actas de algunos de los congresos de 2009, Evangelina Rodríguez Cuadros ha sacado a la luz una edición, cuya consulta ha sido útil y provechosa...» (13). Esa tradición crítica, notablemente enriquecida y seleccionada para que resulten ventajosas sus aportaciones, es la que da cuerpo al que podemos considerar, sin miedo a errar, el acercamiento al Arte nuevo más importante de los últimos años. 